\title{
Role of movement in long-term basal ganglia changes: implications for abnormal motor responses
}

\author{
Nicola Simola1, Micaela Morelli, ${ }^{1,3}$, Giuseppe Frazzitta ${ }^{4,5}$ and Lucia Frau ${ }^{1}$ \\ Section of Neuropsychopharmacology, Department of Biomedical Sciences, University of Cagliari, Cagliari, Italy \\ ${ }^{2}$ Center of Excellence for Neurobiology of Dependence, University of Cagliari, Cagliari, Italy \\ ${ }^{3}$ National Council of Research (CNR), Institute of Neuroscience, Cagliari, Italy \\ ${ }^{4}$ Department of Parkinson Disease Rehabilitation, "Moriggia-Pelascini" Hospital, Gravedona ed Uniti (Como), Italy \\ ${ }^{5}$ Fondazione Europea Ricerca Biomedica (FERB), "S.Isidoro" Hospital, Trescore Balneario, Italy
}

\section{Edited by:}

Hagai Bergman, The Hebrew

University, Israel

\section{Reviewed by:}

Thomas Boraud, Universite de

Bordeaux, CNRS, France

Alexia Pollack, University of

Massachusetts-Boston, USA

*Correspondence:

Micaela Morelli, Section of Neuropsychopharmacology,

Department of Biomedical Sciences,

University of Cagliari, Via Ospedale 72

09124, Cagliari, Italy

e-mail:morelli@unica.it

\begin{abstract}
Abnormal involuntary movements (AIMs) and dyskinesias elicited by drugs that stimulate dopamine receptors in the basal ganglia are a major issue in the management of Parkinson's disease (PD). Preclinical studies in dopamine-denervated animals have contributed to the modeling of these abnormal movements, but the precise neurochemical and functional mechanisms underlying these untoward effects are still elusive. It has recently been suggested that the performance of movement may itself promote the later emergence of drug-induced motor complications, by favoring the generation of aberrant motor memories in the dopamine-denervated basal ganglia. Our recent results from hemiparkinsonian rats subjected to the priming model of dopaminergic stimulation are in agreement with this. These results demonstrate that early performance of movement is crucial for the manifestation of sensitized rotational behavior, indicative of an abnormal motor response, and neurochemical modifications in selected striatal neurons following a dopaminergic challenge. Building on this evidence, this paper discusses the possible role of movement performance in drug-induced motor complications, with a look at the implications for PD management.
\end{abstract}

Keywords: priming, movement, immobilization, zif-268, dynorphin, 6-OHDA, striatonigral, Parkinson's disease
Motor complications induced by dopamine replacement therapy (DRT) are the major untoward effects associated with the pharmacologic management of Parkinson's disease (PD). These complications include end-of-dose deterioration, motor fluctuations, and abnormal motor responses, the latter being very disabling and severely limiting the patient's quality of life. Results obtained in experimental animal models of PD have indicated that pulsatile stimulation of dopamine receptors following DRT is a key step in the emergence of abnormal motor responses, and that these untoward effects are associated with a malfunction in the signal transduction pathway of the dopamine $\mathrm{D}_{1}$ receptor (Gerfen et al., 1990; Nutt, 2007; Santini et al., 2008; Guigoni and Bezard, 2009; Stocchi, 2009). Nevertheless, the precise mechanisms that underlie abnormal motor responses caused by DRT are still to be elucidated.

Recent findings have suggested that the generation of aberrant procedural memories in striatal motor circuits could participate in the manifestation of abnormal motor responses associated with DRT (Calon et al., 2000; Pisani et al., 2005; Jenner, 2008; Simola et al., 2009; Frau et al., 2013). Thus, the striatum plays a major role in processes such as integration of motor signals, acquisition of motor habits, and execution of motor programs, which are all critically regulated by dopamine (Mink, 1996; Packard and Knowlton, 2002; Gerdeman et al., 2003; Tang et al., 2007; Willuhn and Steiner, 2008). Starting from these premises, it has been hypothesized that the dopamine-denervated striatum fails to properly process motor information, and that this may result in an overload of striatal motor circuits following the performance of movement stimulated by drugs that activate dopamine receptors (Picconi et al., 2005; Pisani et al., 2005). This process, in turn, would promote pathologic motor learning, and eventually the onset of abnormal motor responses, such as dyskinesia (Picconi et al., 2005; Jenner, 2008). Therefore, the performance of movement might itself play a role in the emergence of abnormal motor responses caused by DRT. Interestingly, studies in both dopamine-denervated experimental animals and PD patients provide support to this view, by showing that physical activity may influence the severity of abnormal motor responses triggered by repeated administration of dopaminergic drugs (Reuter et al., 1999, 2000; Frazzitta et al., 2012; Aguiar et al., 2013). Moreover, recent evidence obtained in an experimental model of abnormal motor responses in hemiparkinsonian rats has provided a direct demonstration of an important role of movement performance in the emergence of these untoward effects (Simola et al., 2009; Frau et al., 2013).

\section{CRITICAL EVALUATION OF ABNORMAL MOTOR RESPONSES IN EXPERIMENTAL ANIMAL MODELS OF PD}

Studies in experimental animals have dramatically contributed to the modeling of abnormal motor responses induced by dopamin- 
ergic drugs and elucidation of their mechanisms, and important results in this sense have been obtained in the unilaterally 6hydroxydopamine (6-OHDA)-lesioned rat. Briefly, this animal model is characterized by a hemiparkinsonism subsequent to the infusion of 6-OHDA in the nigrostriatal pathway, which manifests as unilateral forelimb akinesia (Simola et al., 2007). Moreover, when treated with drugs that stimulate dopamine receptors, 6-OHDA-lesioned rats display a characteristic contralateral rotational behavior directed away from the site of toxin infusion, which is indicative of the antiparkinsonian effectiveness of the drug (Deumens et al., 2002; Simola et al., 2007). However, it is worth emphasizing that the repeated administration of drugs that stimulate dopamine receptors induces a sensitization in contralateral rotational behavior which reproduces the same biochemical changes observed in rats displaying dyskinetic-like abnormal involuntary movements (AIMs). In fact, abnormal motor responses induced by repeated treatment with dopaminergic drugs can be modeled in 6-OHDA-lesioned rats by measuring two types of behaviors: AIMs and sensitization in contralateral rotational behavior. AIMs consist of repetitive and purposeless movements of limbs and trunk, and are a reliable rodent model of human dyskinesias (Cenci et al., 1998; Lindgren et al., 2007). Sensitization in contralateral rotational behavior is also indicative of abnormal motor responses to dopaminergic drugs, since the intensity of this phenomenon directly correlates with the prodyskinetic potential of these drugs (Henry et al., 1998; Pinna et al., 2006; Carta et al., 2008).

With regard to sensitization in contralateral rotational behavior, it is worth mentioning the priming model. Priming involves a first administration of a dopamine $D_{1} / D_{2}$ receptor agonist (induction phase) that stimulates contralateral rotational behavior, followed, 3 days later, by the administration of a highly dyskinetic $D_{1}$ receptor agonist (expression phase), at otherwise scarcely effective doses on rotational behavior (Morelli et al., 1989). Primed hemiparkinsonian rats display a vigorous contralateral rotational behavior on the expression phase, which is associated with neurochemical modifications in the striatum that are peculiar to experimental paradigms of prolonged administration of dopaminergic drugs (Pollack et al., 1997; van de Witte et al., 1998; Simola et al., 2007; Scholz et al., 2008; Nadjar et al., 2009). This evidence, therefore, indicates that the priming model is highly valuable for investigating the mechanisms that underlie abnormal motor responses to dopaminergic drugs in hemiparkinsonian rats.

\section{MOVEMENT PERFORMANCE FOLLOWING INITIAL DOPAMINERGIC STIMULATION ENABLES THE MANIFESTATION OF SENSITIZED ROTATIONAL BEHAVIOR IN PRIMED HEMIPARKINSONIAN RATS}

Hemiparkinsonian 6-OHDA-lesioned drug-naïve rats that are treated with the $\mathrm{D}_{1} / \mathrm{D}_{2}$ agonist apomorphine $(0.2 \mathrm{mg} / \mathrm{kg}$, s.c.) during priming induction and left to rotate freely in response to the drug exhibit a marked contralateral rotational behavior when challenged 3 days later with the $\mathrm{D}_{1}$ receptor agonist 1-Phenyl2,3,4,5-tetrahydro-(1H)-3-benzazepine-7,8-diol (SKF 38393, 3 $\mathrm{mg} / \mathrm{kg}$, s.c.), which is indicative of an abnormal motor response
(Morelli et al., 1989; Simola et al., 2009). This behavioral effect of SKF 38393 has been found to be almost completely abolished in rats subjected to the same pharmacologic treatment that were immobilized for $1 \mathrm{~h}$ in a restrainer apparatus during priming induction, so that they could not perform rotational behavior in response to apomorphine (Figure 1; Simola et al., 2009). Importantly, immobilization has been demonstrated to suppress priming expression only when imposed concomitantly to apomorphine administration, but not immediately before or immediately after priming induction, therefore excluding a non-specific effect of immobilization (Simola et al., 2009). Moreover, the influence of immobilization on the effects of SKF 38393 has been shown not to be affected by the elevation in stress hormones that is associated with this procedure. This is clearly demonstrated by the finding that immobilization during priming induction retained the suppressant effects on priming expression even in rats treated with metyrapone (Simola et al., 2009), which prevents the elevation in stress glucocorticoid hormones that may be caused by immobilization (Calvo and Volosin, 2001). This finding is very important, since previous evidence has demonstrated that stress may have a profound influence on the behavioral and neurochemical effects of movement performance (Howells et al., 2005). Taken together, these findings indicate that the suppression of priming expression in rats immobilized during priming induction is attributable solely to the fact that immobilization prevented rats from performing movement in

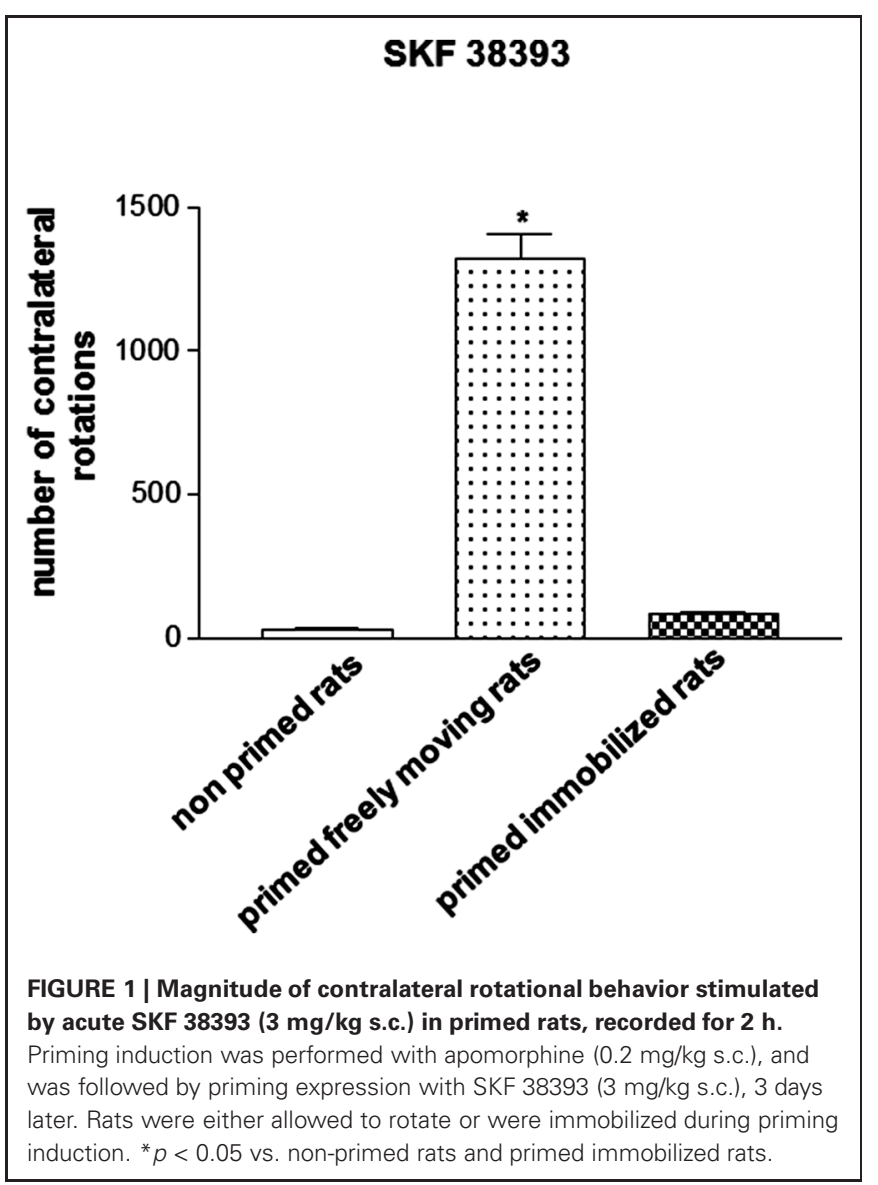


response to the initial dopaminergic stimulation (Simola et al., 2009). Therefore, the results obtained in hemiparkinsonian rats subjected to the priming model have provided the first direct demonstration that the performance of drug-stimulated movement may be crucial for the later emergence of abnormal motor responses to repetitive administration of dopaminergic drugs.

\section{MOTOR PERFORMANCE FOLLOWING INITIAL DOPAMINERGIC STIMULATION TRIGGERS NEUROCHEMICAL MODIFICATIONS IN SELECTED STRIATAL EFFERENT NEURONS OF PRIMED HEMIPARKINSONIAN RATS}

In order to evaluate whether or not movement performance triggers changes indicative of neuronal long-term modifications, several biochemical and molecular parameters have been evaluated in the striatum of hemiparkinsonian drug-naïve and primed rats. The results obtained have demonstrated that both sensitized rotational behavior on the expression of priming and dyskinetic-like movements in dopamine-denervated animals repeatedly treated with dopaminergic drugs are associated with long-term changes in the production of striatal cyclic adenosine monophosphate (cAMP; Pinna et al., 1997), phosphorylation of dopamine- and cAMP-regulated neuronal phosphoprotein (DARPP-32; Santini et al., 2007), and expression of mRNAs encoding for different proteins and immediate early genes (IEGs; Barone et al., 1994; Cenci et al., 1998, 2009; Crocker et al., 1998; van de Witte et al., 1998; Carta et al., 2003, 2008; Aubert et al., 2005). In this regard, the IEG zif-268 has recently been shown to be a useful marker of neuronal modification that involves striatal efferent pathways in animal models of abnormal motor responses (Carta et al., 2008, 2010).

zif-268 (also known as Egr-1, Krox-24, NGFI-A, or Zenk) belongs to a class of inducible IEGs that encode regulatory transcription factors, and that have been implicated in diverse processes in a variety of cell types, including cell growth, differentiation, and apoptosis in response to extracellular stimuli (Gashler and Sukhatme, 1995). In the brain, zif-268 mRNA and protein are constitutively expressed in several areas, such as the neocortex and hippocampus, and, of great importance in PD, the striatum (Christy et al., 1988; Mack et al., 1990; Schlingensiepen et al., 1991; Worley et al., 1991). Moreover, zif-268 can be rapidly and transiently induced by a variety of pharmacologic and physiologic stimuli, including neurotransmitters, growth factors, peptides, depolarization, seizures, ischemia, and brain injury or cellular stress (Gashler and Sukhatme, 1995; Beckmann and Wilce, 1997). As mentioned above, zif-268 may represent a useful and sensitive neurochemical marker in the evaluation of abnormal motor and neuronal responses associated with the onset of dyskinesia in dopamine-denervated animals treated with dopaminergic drugs (Carta et al., 2005, 2008). Thus, drugs such as L-3,4dihydroxyphenylalanine (L-DOPA) and SKF 38393, which induce severe dyskinetic-like movements, markedly increase the levels of zif-268 mRNA in striatal neurons, after both acute and subchronic treatment (Carta et al., 2005, 2008, 2010). In contrast, treatment with drugs that elicit a scarce dyskinetic-like response, such as ropinirole, do not produce any elevation in zif-268 (Carta et al., 2010). Notably, the expression of mRNA encoding for zif-
268 was selectively increased in the direct striatonigral pathway, which seems to be the pathway most involved in development of dyskinetic movements (Carta et al., 2010).

Similar to these findings, experiments in 6-OHDA-lesioned hemiparkinsonian rats subjected to the priming model have shown that the administration of the $D_{1}$ receptor agonist SKF 38393 on priming expression induces an increase in striatal zif-268 mRNA (Frau et al., 2013). Moreover, analysis at the singlecell level showed that only enkephalin $(-)$ striatonigral neurons, which belong to the direct pathway, displayed a significantly higher expression of zif-268 following SKF 38393. On the other hand, enkephalin $(+)$ striatopallidal neurons, which belong to the indirect pathway, that is less involved in abnormal motor responses elicited by dopaminergic drugs (Carta et al., 2010), did not show any significant modifications in the levels of zif-268. No significant differences in this effect were observed when the results from primed rats that performed rotational behavior during priming induction were compared with those obtained in rats that were immobilized on priming induction (Frau et al., 2013). This latter finding seems to suggest that modifications in zif-268 mRNA levels observed in the enkephalin $(-)$ striatonigral neurons of hemiparkinsonian rats during priming expression are not influenced by the fact that the rats could perform rotational behavior during priming induction. In this regard, it is worth mentioning that enkephalin $(-)$ striatopallidal neurons include two subpopulations: substance $\mathrm{P}(+)$ and dynorphin $(+)$ neurons. Analysis of zif-268 in these neuronal populations has demonstrated a selective increase of this IEG in dynorphin $(+)$ striatonigral neurons of rats primed with SKF 38393 that performed rotational behavior during priming induction, compared with primed rats immobilized on priming induction (Figure 2). This finding demonstrates, in the first place, a critical role of drug-stimulated movement performance in the emergence of neurochemical modifications in striatal neurons of dopamine-denervated rats subjected to repetitive administration of dopaminergic drugs, and that the dynorphin $(+)$ neurons are selectively involved in the long-term modifications caused by early motor performance in the priming model (Frau et al., 2013). Moreover, the intensity of rotational behavior on priming expression was found to correlate positively with the levels of zif-268 mRNA in dynorphin(+) neurons (Frau et al., 2013). This finding is very interesting, as it indicates a relationship between early performance of drug-stimulated movement and appearance of neurochemical adaptations associated with an abnormal motor response to dopaminergic drugs (Frau et al., 2013). With regard to the modifications in the levels of $z i f-268$ in the priming model, it is also relevant to observe that zif-268 is rapidly induced in certain forms of learning, or after long-term potentiation (Lanahan and Worley, 1998; O’Donovan et al., 1999; Tischmeyer and Grimm, 1999; Bozon et al., 2002), and has recently been shown to be necessary for the formation of different forms of long-term memory (Jones et al., 2001). Together with the results obtained in the priming model, this finding would provide support to the hypothesis suggesting that abnormal motor responses to repetitive administration of dopaminergic drugs in conditions of dopaminergic denervation might involve the generation of abnormal procedural memories in striatal motor circuits. 

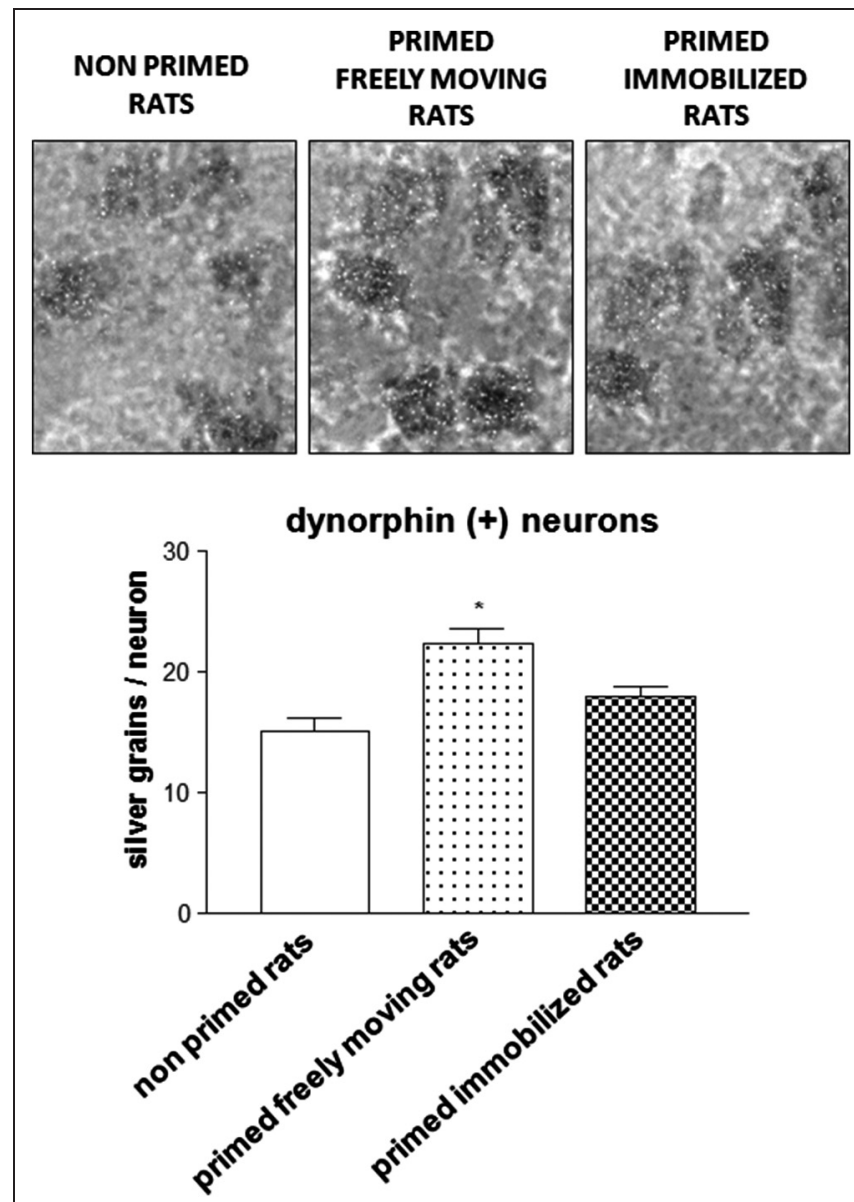

FIGURE 2 | Photomicrograph and histogram showing zif-268 mRNA expression as number of silver grains/neuron in dynorphin(+) striatonigral neurons from the 6-OHDA-lesioned dorsolateral striatum of rats subjected to priming. Priming induction was performed with apomorphine $(0.2 \mathrm{mg} / \mathrm{kg}$ s.c.), and was followed by priming expression with SKF 38393 (3 mg/kg s.c.), 3 days later. Rats were either allowed to rotate or were immobilized during priming induction. Rats were sacrificed $2 \mathrm{~h}$ after SKF 38393 administration to perform in situ hybridization studies. ${ }^{*} p<0.05$ vs. non-primed rats and primed immobilized rats.

\section{CONCLUSIONS}

The results obtained in 6-OHDA-lesioned hemiparkinsonian rats subjected to the priming model demonstrate that the early performance of drug-stimulated movement promotes the later emergence of an abnormal motor response and striatal neurochemical adaptations following the subsequent administration of dopaminergic drugs with pro-dyskinetic potential (Simola et al., 2009; Frau et al., 2013). These results may appear to contrast with recent studies in experimental animals and PD patients that demonstrate how performance of movement in the form of physical training and exercise may improve motor deficits and even ameliorate dyskinesias (Goodwin et al., 2008; Döbrössy et al., 2010; Frazzitta et al., 2010; Dutra et al., 2012; Frazzitta et al., 2012; Aguiar et al., 2013). In this regard, it is worth considering that extensive neuroplasticity takes place in the striatum, which regulates movement performance, that physical activity may interfere with these neuroplastic phenomena, eventually influencing the execution of movement at a later time, and that neuroplasticity can be profoundly modified in conditions of dopamine denervation (Tillerson et al., 2001; Packard and Knowlton, 2002; Smith and Zigmond, 2003; Schouenborg, 2004; Graybiel, 2005). Therefore, it can be hypothesized that drug-stimulated movement and voluntary physical activity, given their different nature, might result in distinct neuroplastic adaptations in the dopamine-denervated striatum, leading to different effects on abnormal motor responses. Thus, irrepressible movement stimulated by dopaminergic drugs could overload striatal motor circuits with redundant information and promote pathologic motor learning, eventually triggering the generation of aberrant habits, which may manifest as abnormal motor responses, such as dyskinesias (Calon et al., 2000; Picconi et al., 2005; Jenner, 2008). On the other hand, physical activity in the framework of therapeutic programs could compete with purposeless movements triggered by dopaminergic drugs, therefore counteracting the generation of abnormal procedural mnemonic traces in the striatum, and thus ameliorating motor performance and mitigating dyskinesias.

In summary, the results obtained in hemiparkinsonian rats subjected to the priming model suggest that the performance of movement in response to an initial stimulation of dopamine receptors in the dopamine-denervated striatum plays a key role in the emergence of both abnormal motor responses and specific neuroadaptive changes in response to a later dopaminergic challenge. These results may help understand the initial molecular events that are at the basis of motor complications, such as dyskinesia, associated with DRT used to manage PD.

\section{AUTHOR CONTRIBUTIONS}

Nicola Simola and Lucia Frau: writing of the first draft of the manuscript and review. Giuseppe Frazzitta and Micaela Morelli: manuscript review and critique.

\section{ACKNOWLEDGMENTS}

Dr. Nicola Simola gratefully acknowledges Sardinia Regional Government for the financial support (P.O.R. Sardegna F.S.E. Operational Programme of the Autonomous Region of Sardinia, Euro pean Social Fund 2007-2013-Axis IV Human Resources, Objective 1.3, Line of Activity 1.3.1 "Avviso di chiamata per il finanziamento di Assegni di Ricerca"). Dr. Lucia Frau acknowledges the Sardinian Regional Government for financial support (Legge Regionale 7 Agosto 2007, N.7, attivazione contratto con giovani ricercatori, contratto 150/2013).

\section{REFERENCES}

Aguiar, A. S. Jr., Moreira, E. L., Hoeller, A. A., Oliveira, P. A., Córdova, F. M., Glaser, V., et al. (2013). Exercise attenuates levodopa-induced dyskinesia in 6-hydroxydopamine- lesioned mice. Neuroscience 243, 46-53. doi: 10.1016/j. neuroscience.2013.03.039

Aubert, I., Guigoni, C., Håkansson, K., Li, Q., Dovero, S., Barthe, N., et al. (2005). Increased D1 dopamine receptor signaling in levodopainduced dyskinesia. Ann. Neurol. 57, 17-26. doi: 10.1002/ana.20296

Barone, P., Morelli, M., Popoli, M., Cicarelli, G., Campanella, G., and Di Chiara, G. (1994). Behavioural sensitization in 6-hydroxydopamine lesioned rats involves the dopamine signal transduction: changes in DARPP-32 phosphorylation. Neuroscience 61, 867-873. doi: 10. 1016/0306-4522(94)90409-X 
Beckmann, A. M., and Wilce, P. A. (1997). Egr transcription factors in the nervous system. Neurochem. Int. 31, 477-510. doi: 10.1016/S01970186(97)00001-6

Bozon, B., Davis, S., and Laroche, S. (2002). Regulated transcription of the immediate-early gene Zif268: mechanisms and gene dosagedependent function in synaptic plasticity and memory formation. Hippocampus 12, 570-577. doi: 10. 1002/hipo.10100

Calon, F., Grondin, R., Morissette, M., Goulet, M., Blanchet, P. J., Di Paolo, T., et al. (2000). Molecular basis of levodopa-induced dyskinesias. Ann. Neurol. 47(Suppl 1), S70-S78.

Calvo, N., and Volosin, M. (2001). Glucocorticoid and mineralocorticoid receptors are involved in the facilitation of anxiety-like response induced by restraint. Neuroendocrinology 73, 261-271. doi: 10.1159/000054643

Carta, A. R., Fenu, S., Pala, P., Tronci, E., and Morelli, M. (2003). Selective modifications in GAD67 mRNA levels in striatonigral and striatopallidal pathways correlate to dopamine agonist priming in 6-hydroxydopamine-lesioned rats. Eur. J. Neurosci. 18, 2563-2572. doi: $\quad 10.1046 /$ j.1460-9568.2003. 02983.x

Carta, A. R., Frau, L., Pinna, A., and Morelli, M. (2010). Dyskinetic potential of dopamine agonists is associated with different striatonigral/striatopallidal zif268 expression. Exp. Neurol. 224, 395-402. doi: 10.1016/j.expneurol. 2010.04.016

Carta, A. R., Frau, L., Pinna, A., Pontis, S., Simola, N., Schintu, N., et al. (2008). Behavioral and biochemical correlates of the dyskinetic potential of dopaminergic agonists in the 6-OHDA lesioned rat. Synapse 62, 524-533. doi: 10.1002/syn.20527

Carta, A. R., Tronci, E., Pinna, A., and Morelli, M. (2005). Different responsiveness of striatonigral and striatopallidal neurons to L-DOPA after a subchronic intermittent LDOPA treatment. Eur. J. Neurosci. 21, 1196-1204. doi: 10.1111/j.14609568.2005.03944.x

Cenci, M. A., Lee, C. S., and Björklund, A. (1998). L-DOPA-induced dyskinesia in the rat is associated with striatal overexpression of prodynorphin- and glutamic acid decarboxylase mRNA. Eur. J. Neurosci. 10, 2694-2706. doi: 10.1046/j. 1460-9568.1998.00285.x

Cenci, M. A., Ohlin, K. E., and Rylander, D. (2009). Plastic effects of L-
DOPA treatment in the basal ganglia and their relevance to the development of dyskinesia. Parkinsonism Relat. Disord. 15, S59-S63. doi: 10. 1016/S1353-8020(09)70782-5

Christy, B. A., Lau, L. F., and Nathans, D. (1988). A gene activated in mouse 3T3 cells by serum growth factors encodes a protein with "zinc finger" sequences. Proc. Natl. Acad. Sci. U S A 85, 7857-7861. doi: 10.1073/pnas. 85.21.7857

Crocker, S. J., Morelli, M., Wigle, N., Nakabeppu, Y., and Robertson, G. S. (1998). D1-receptorrelated priming is attenuated by antisense-mediated 'Knockdown' of FosB expression. Brain Res. Mol. Brain Res. 53, 69-77. doi: 10. 1016/S0169-328X(97)00281-7

Deumens, R., Blokland, A., and Prickaerts, J. (2002). Modeling Parkinson's disease in rats: an evaluation of 6-OHDA lesions of the nigrostriatal pathway. Exp. Neurol. 175, 303-317. doi: 10.1006/exnr.2002.7891

Döbrössy, M., Busse, M., Piroth, T., Rosser, A., Dunnett, S., and Nikkhah, G. (2010). Neurorehabilitation with neural transplantation. Neurorehabil. Neural Repair 24, 692-701. doi: 10. $1177 / 1545968310363586$

Dutra, M. F., Jaeger, M., Ilha, J., Kalil-Gaspar, P. I., Marcuzzo, S., and Achaval, M. (2012). Exercise improves motor deficits and alters striatal GFAP expression in a 6-OHDA-induced rat model of Parkinson's disease. Neurol. Sci. 33, 1137-1144. doi: 10.1007/s10072011-0925-5

Frau, L., Morelli, M., and Simola, N. (2013). Performance of movement in hemiparkinsonian rats influences the modifications induced by dopamine agonists in striatal efferent dynorphinergic neurons. Exp. Neurol. 247, 663-672. doi: 10. 1016/j.expneurol.2013.03.002

Frazzitta, G., Bertotti, G., Morelli, M., Riboldazzi, G., Pelosin, E., Balbi, P., et al. (2012). Rehabilitation improves dyskinesias in Parkinsonian patients: a pilot study comparing two different rehabilitative treatments. NeuroRehabilitation 30, 295301. doi: 10.3233/NRE-2012-0758

Frazzitta, G., Bertotti, G., Uccellini, D., and Maestri, R. (2010). Parkinson's disease rehabilitation: a pilot study with 1 year follow up. Mov. Disord. 25, 1762-1763. doi: 10.1002/mds. 23316

Gashler, A., and Sukhatme, V. P. (1995). Early growth response protein 1 (Egr-1): prototype of a zinc-finger family of transcription factors. Prog. Nucleic Acid Res. Mol. Biol. 50, 191-224. doi: 10. 1016/S0079-6603(08)60815-6

Gerdeman, G. L., Partridge, J. G., Lupica, C. R., and Lovinger, D. M. (2003). It could be habit forming: drugs of abuse and striatal synaptic plasticity. Trends Neurosci. 26, 184-192. doi: 10.1016/S01662236(03)00065-1

Gerfen, C. R., Engber, T. M., Mahan, L. C., Susel, Z., Chase, T.N., Monsma, F. J. Jr., et al. (1990). D1 and D2 dopamine receptor-regulated gene expression of striatonigral and striatopallidal neurons. Science 250, 1429-1432. doi: 10.1126/science. 2147780

Goodwin, V. A., Richards, S. H., Taylor, R. S., Taylor, A. H., and Campbell, J. L. (2008). The effectiveness of exercise interventions for people with Parkinson's disease: a systematic review and meta-analysis. Mov. Disord. 23, 631-640. doi: 10. $1002 / \mathrm{mds} .21922$

Graybiel, A. M. (2005). The basal ganglia: learning new tricks and loving it. Curr. Opin. Neurobiol. 15, 638-644. doi: 10.1016/j.conb.2005. 10.006

Guigoni, C., and Bezard, E. (2009). Involvement of canonical and noncanonical D1 dopamine receptor signalling pathways in L-dopainduced dyskinesia. Parkinsonism Relat. Disord. 15(Suppl. 3), S64S67. doi: 10.1016/S1353-8020(09) 70783-7

Henry, B., Crossman, A. R. and Brotchie, J. M. (1998). Characterization of enhanced behavioral responses to L-DOPA following repeated administration in the 6-hydroxydopamine-lesioned rat model of Parkinson's disease. Exp. Neurol. 151, 334-342. doi: 10. 1006/exnr.1998.6819

Howells, F. M., Russell, V. A., Mabandla, M. V., and Kellaway, L. A. (2005). Stress reduces the neuroprotective effect of exercise in a rat model for Parkinson's disease. Behav. Brain Res. 165, 210-220. doi: 10.1016/j.bbr.2005. 06.044

Jenner, P. (2008). Molecular mechanisms of L-DOPA-induced dyskinesia. Nat. Rev. Neurosci. 9, 665-677. doi: 10.1038/nrn2471

Jones, M. W., Errington, M. L., French, P. J., Fine, A., Bliss, T. V. P., Garel, S., et al. (2001). A requirement for the immediate early gene Zif268 in the expression of late LTP and long-term memories. Nat. Neurosci. 4, 289-296. doi: 10.1038/ 85138
Lanahan, A., and Worley, P. (1998). Immediate-early genes and synaptic function. Neurobiol. Learn. Mem. 70, 37-43. doi: 10.1006/nlme.1998. 3836

Lindgren, H. S., Rylander, D., Ohlin, K. E., Lundblad, M., and Cenci, M. A. (2007). The "motor complication syndrome" in rats with 6-OHDA lesions treated chronically with LDOPA: relation to dose and route of administration. Behav. Brain Res. 177, 150-159. doi: 10.1016/j.bbr. 2006.09.019

Mack, K., Day, M., Milbrandt, J., and Gottlieb, D. I. (1990). Localization of the NGFI-A protein in the rat brain. Brain Res. Mol. Brain Res. 8, 177-180. doi: 10.1016/0169328X(90)90062-I

Mink, J. W. (1996). The basal ganglia: focused selection and inhibition of competing motor programs. Prog Neurobiol. 50, 381-425. doi: 10. 1016/S0301-0082(96) 00042-1

Morelli, M., Fenu, S., Garau, L., and Di Chiara, G. (1989). Time and dose dependence of the 'priming' of the expression of dopamine receptor supersensitivity. Eur. J. Pharmacol. 162, 329-335. doi: 10. 1016/0014-2999(89) 90296-3

Nadjar, A., Gerfen, C. R., and Bezard, E. (2009). Priming for l-dopa-induced dyskinesia in Parkinson's disease: a feature inherent to the treatment or the disease? Prog. Neurobiol. 87, 1-9. doi: 10.1016/j.pneurobio.2008. 09.013

Nutt, J. G. (2007). Continuous dopaminergic stimulation: Is it the answer to the motor complications of Levodopa? Mov. Disord. 22, 1-9. doi: 10.1002/mds.21060

O’Donovan, K. J., Tourtellotte, W. G., Milbrandt, J., and Baraban, J. M. (1999). The EGR family of transcriptionregulatory factors: progress at the interface of molecular and systems neuroscience. Trends Neurosci. 22, 167-173. doi: 10.1016/S01662236(98)01343-5

Packard, M. G., and Knowlton, B. J. (2002). Learning and memory functions of the Basal Ganglia. Annu. Rev. Neurosci. 25, 563-593. doi: 10.1146/annurev.neuro.25.1127 01.142937

Picconi, B., Pisani, A., Barone, I., Bonsi, P., Centonze, D., Bernardi, G., et al. (2005). Pathological synaptic plasticity in the striatum: implications for Parkinson's disease. Neurotoxicology 26, 779-783. doi: 10.1016/j. neuro.2005.02.002 
Pinna, A., Morelli, M., Drukarch, B., and Stoof, J. C. (1997). Priming of 6-hydroxydopamine-lesioned rats with L-DOPA or quinpirole results in an increase in dopamine D1 receptor-dependent cyclic AMP production in striatal tissue. Eur. J. Pharmacol. 331, 23-26. doi: 10. 1016/S0014-2999(97)01067-4

Pinna, A., Pontis, S., and Morelli, M. (2006). Expression of dyskinetic movements and turning behaviour in subchronic L-DOPA 6hydroxydopamine-treated rats is influenced by the testing environment. Behav. Brain Res. 171, 175-178. doi: 10.1016/j.bbr. 2006.03.021

Pisani, A., Centonze, D., Bernardi, G., and Calabresi, P. (2005). Striatal synaptic plasticity: implications for motor learning and Parkinson's disease. Mov. Disord. 20, 395-402. doi: $10.1002 / \mathrm{mds} .20394$

Pollack, A. E., Turgeon, S. M., and Fink, J. S. (1997). Apomorphine priming alters the response of striatal outflow pathways to D2 agonist stimulation in 6-hydroxydopamine-lesioned rats. Neuroscience 79, 79-93. doi: 10. 1016/S0306-4522(96)00681-1

Reuter, I., Engelhardt, M., Stecker, K., and Baas, H. (1999). Therapeutic value of exercise training in Parkinson's disease. Med. Sci. Sports Exerc. 31, 1544-1549. doi: 10. 1097/00005768-199911000-00008

Reuter, I., Harder, S., Engelhardt, M., and Baas, H. (2000). The effect of exercise on pharmacokinetics and pharmacodynamics of levodopa. Mov. Disord. 15, 862-868. doi: 10.1002/15318257(200009)15:5<862::AIDMDS1015>3.0.CO;2-S

Santini, E., Valjent, E., and Fisone, G. (2008). Parkinson's disease: levodopa-induced dyskinesia and signal transduction. FEBS J. 275, 1392-1399. doi: 10.1111/j. 1742-4658.2008.06296.x

Santini, E., Valjent, E., Usiello, A., Carta, M., Borgkvist, A., Girault, J. A., et al. (2007). Critical involvement of cAMP/DARPP-32 and extracellular signal-regulated protein kinase signaling in LDOPA-induced dyskinesia. J. Neurosci. 27, 6995-7005. doi: 10. 1523/JNEUROSCI.0852-07.2007

Schlingensiepen, K. H., Luno, K., and Brysch, W. (1991). High basal expression of the zif/268 immediate early gene in cortical layers IV and VI, in CAl and in the corpus striatum-an in situ hybridization study. Neurosci. Lett. 122, $67-$ 70. doi: 10.1016/0304-3940(91) 90195-Y

Scholz, B., Svensson, M., Alm, H., Sköld, K., Fälth, M., Kultima, K., et al. (2008). Striatal proteomic analysis suggests that first L-dopa dose equates to chronic exposure. PLoS One 3:e1589. doi: 10.1371/journal. pone.0001589

Schouenborg, J. (2004). Learning in sensorimotor circuits. Curr. Opin. Neurobiol. 14, 693-697. doi: 10. 1016/j.conb.2004.10.009

Simola, N., Di Chiara, G., Daniels, W. M., Schallert, T., and Morelli, M. (2009). Priming of rotational behavior by a dopamine receptor agonist in Hemiparkinsonian rats: movement-dependent induction. Neuroscience 158, 1625-1631. doi: $\quad 10.1016 /$ j.neuroscience.2008. 11.009

Simola, N., Morelli, M., and Carta, A. R. (2007). The 6-hydroxydopamine model of Parkinson's disease. Neurotox. Res. 11, 151-167. doi: 10. 1007/BF03033565
Smith, A. D., and Zigmond, M. J. (2003). Can the brain be protected through exercise? Lessons from an animal model of parkinsonism. Exp. Neurol. 184, 3139. doi: 10.1016/j.expneurol.2003. 08.017

Stocchi, F. (2009). The therapeutic concept of continuous dopaminergic stimulation (CDS) in the treatment of Parkinson's disease. Parkinsonism Relat. Disord. 15(Suppl. 3), S68S71. doi: 10.1016/S1353-8020(09) 70784-9

Tang, C., Pawlak, A. P., Prokopenko, V., and West, M. O. (2007). Changes in activity of the striatum during formation of a motor habit. Eur. J. Neurosci. 25, 1212-1227. doi: $\quad 10.1111 /$ j.1460-9568.2007. 05353.x

Tillerson, J. L., Cohen, A. D., Philhower, J., Miller, G. W., Zigmond, M. J., and Schallert, T. (2001). Forced limb-use effects on the behavioral and neurochemical effects of 6hydroxydopamine. J. Neurosci. 21, 4427-4435.

Tischmeyer, W., and Grimm, R. (1999). Activation of immediate early genes and memory formation. Cell. Mol. Life Sci. 55, 564-574. doi: 10 . 1007/s000180050315

van de Witte, S. V., Drukarch, B., Stoof, J. C., and Voorn, P. (1998). Priming with L-DOPA differently affects dynorphin and substance $\mathrm{P}$ mRNA levels in the striatum of 6-hydroxydopamine-lesioned rats after challenge with dopamine D1-receptor agonist. Brain Res. Mol. Brain Res. 61, 219-223. doi: $\quad 10.1016 /$ S0169-328X(98) 00214-9

Willuhn, I., and Steiner, $\mathrm{H}$. (2008). Motor-skill learning in a novel running-wheel task is dependent on D1 dopamine receptors in the striatum. Neuroscience 153, 249-258. doi: 10.1016/j.neuroscience.2008. 01.041

Worley, P. F., Christy, B. A., Nakabeppu, Y., Bhat, R. V., Cole, A. J., and Baraban, J. M. (1991). Constitutive expression of zif268 in neocortex is regulated by synaptic activity. Proc. Natl. Acad. Sci. U S A 88, 5106-5110. doi: 10.1073/pnas. 88.12 .5106

Conflict of Interest Statement: The authors declare that the research was conducted in the absence of any commercial or financial relationships that could be construed as a potential conflict of interest.

Received: 29 July 2013; accepted: 30 September 2013; published online: 23 October 2013.

Citation: Simola N, Morelli M, Frazzitta $G$, and Frau L (2013) Role of movement in long-term basal ganglia changes: implications for abnormal motor responses. Front. Comput. Neurosci. 7:142. doi: 10.3389/fncom.2013.00142

This article was submitted to the journal Frontiers in Computational Neuroscience.

Copyright (C) 2013 Simola, Morelli, Frazzitta and Frau. This is an openaccess article distributed under the terms of the Creative Commons Attribution License (CC BY). The use, distribution or reproduction in other forums is permitted, provided the original author(s) or licensor are credited and that the original publication in this journal is cited, in accordance with accepted academic practice. No use, distribution or reproduction is permitted which does not comply with these terms. 